\title{
BMJ Global Health Difficulties faced by older Rohingya (forcibly displaced Myanmar nationals) adults in accessing medical services amid the COVID-19 pandemic in Bangladesh
}

Sabuj Kanti Mistry (10) ,1,2,3,4 ARM Mehrab Ali (1) , ${ }^{1,5}$ Uday Narayan Yadav, ${ }^{2,6}$ Md. Nazmul Huda, ${ }^{7,8}$ Saruna Ghimire, ${ }^{9}$ Amy Bestman, ${ }^{10}$ Md. Belal Hossain (D) , 3,11 Sompa Reza, ${ }^{12}$ Rubina Qasim, ${ }^{13}$ Mark F Harris ${ }^{2}$

To cite: Mistry SK, Ali ARMM, Yadav UN, et al. Difficulties faced by older Rohingya (forcibly displaced Myanmar nationals) adults in accessing medical services amid the COVID-19 pandemic in Bangladesh. BMJ Global Health 2021;6:e007051. doi:10.1136/ bmjgh-2021-007051

Handling editor Seema Biswas - Additional supplemental material is published online only. To view, please visit the journal online (http://dx.doi.org/10. 1136/bmjgh-2021-007051).

Received 30 July 2021 Accepted 17 November 2021

Check for updates

(C) Author(s) (or their employer(s)) 2021. Re-use permitted under CC BY-NC. No commercial re-use. See rights and permissions. Published by BMJ.

For numbered affiliations see end of article.

Correspondence to Sabuj Kanti Mistry; smitra411@gmail.com

\section{ABSTRACT}

Background COVID-19 has seriously disrupted health services in many countries including Bangladesh. This research aimed to explore whether Rohingya (forcefully displaced Myanmar nationals) older adults in Bangladesh faced difficulties accessing medicines and routine medical care services amid this pandemic.

Methods This cross-sectional study was conducted among 416 Rohingya older adults aged 60 years and above residing in Rohingya refugee camps situated in the Cox's Bazar district of Bangladesh and was conducted in October 2020. A purposive sampling technique was followed, and participants' perceived difficulties in accessing medicines and routine medical care were noted through face-to-face interviews. Binary logistic regression models determined the association between outcome and explanatory variables.

Results Overall, one-third of the participants reported difficulties in accessing medicines and routine medical care. Significant factors associated with facing difficulties accessing medicine included feelings of Ioneliness (adjusted OR (AOR) 3.54, 95\% Cl 1.93 to 6.48), perceptions that older adults were at the highest risk of COVID-19 (AOR 3.35, 95\% Cl 1.61 to 6.97) and required additional care during COVID-19 (AOR $6.89,95 \% \mathrm{Cl} 3.62$ to 13.13 ). Also, the notable factors associated with difficulties in receiving routine medical care included living more than 30 min walking distance from the health centre (AOR 3.57, 95\% $\mathrm{Cl} 1.95$ to 6.56), feelings of loneliness (AOR $2.20,95 \% \mathrm{Cl} 1.25$ to $3.87)$, perception that older adults were at the highest risk of COVID-19 (AOR 2.85, 95\% Cl 1.36 to 5.99) and perception that they required additional care during the pandemic (AOR 4.55, 95\% Cl 2.48 to 8.35).

Conclusion Many Rohingya older adults faced difficulties in accessing medicines and routine medical care during this pandemic. This call for policy-makers and relevant stakeholders to re-assess emergency preparedness plans including strategies to provide continuing care.

\section{Key questions}

What is already known?

- Older adults are more susceptible to increased risk of morbidity and mortality due to COVID-19.

- Rohingya people or forcibly displaced Myanmar nationals resides in an overpopulated camp environment with limited access to health and sanitation facilities.

- COVID-19 can further exacerbate the healthcare service delivery due to lockdown measures and social isolation.

What are the new findings?

- Overall, one-third of the older adults reported difficulties in accessing medicine and routine medical care.

- Key factors influencing access were distance to healthcare facilities, loneliness and perceived vulnerability of older people.

What do the new findings imply?

- Emergency preparedness plans should be revised, incorporating strategies to ensure adequate access to routine medical services, particularly for vulnerable people like older adults.

\section{BACKGROUND}

The greatest public health challenge of our time, the COVID-19 pandemic, has already caused more than four million deaths and confirmedly infected more than 236 million individuals worldwide as of 8 October $2021 .{ }^{1}$ By the same date, there were more than 1.5 million confirmed cases and 27654 deaths in Bangladesh. ${ }^{1}$ Although everybody is at risk of COVID-19 infection, the intensity of the health and economic implications of the pandemic has been stronger in some segments of the population than in others. ${ }^{2}$ 
Since the emergence of the COVID-19, it has been well documented that older adults are at a higher risk of infection and death compared with the general population. ${ }^{3-5}$ Emerging evidence also shows that older adults with preexisting chronic conditions are at increased risk of health consequences. ${ }^{6}$

Displaced populations and refugees, who have had to flee from their home countries due to political instability, war and natural disasters, ${ }^{7}$ are particularly at risk of COVID-19 because they reside in populated refugee camps where social distancing is difficult. ${ }^{8}$ Moreover, basic sanitation and hygiene facilities are meagre in the camp environment, and the availability of health services is limited with inadequate opportunities for proper diagnosis and management in an outbreak. ${ }^{9}$

The Rohingya people, a population groups that has faced the most persecution and human rights abuses globally, ${ }^{10}$ are Muslim minorities of Myanmar residing primarily in Rakhine state. Following years of conflict, Rohingya people started to flee in large numbers from their land on 25 August 2017 after brutal attacks set off by the Myanmar militants. ${ }^{11}$ Bangladesh has shown laudable openness and empathy towards the displaced and vulnerable Rohingya population, providing temporary shelter and establishing the world's largest refugee camp in Cox's Bazar, the south-eastern district of Bangladesh. ${ }^{12}$ According to the latest report by United Nations High Commissioner for Refugees, the total number of inhabitants in the camp reached 860,365 , with $4 \%$ older adults aged 60 years and above. ${ }^{13}$

With high population density, ranging from 40000 to 70000 inhabitants per square kilometre, the Rohingya refugee camp areas are congested and overpopulated, ${ }^{14}$ which facilitates the rapid spread of coronavirus. ${ }^{15}$ As of 3 October 2021, there were 3084 confirmed COVID-19 positive cases and 32 deaths in the camp. ${ }^{16}$ According to an Inter Sectoral Coordination Group report, ${ }^{17}$ there were 129 health posts, 56 health centres, and only 10 hospitals for the entire Rohingya population residing in 34 camps where the hospital to population ratio is 1:130 000. This lack of health facilities makes it even more difficult to manage the outbreak and care for other chronic conditions contributing to a syndemic impact of the current COVID-19 pandemic. ${ }^{18}$ Moreover, there are widespread misconceptions regarding the prevention, spread and management of COVID-19 among the older adults in the camps, which may further exacerbate the condition and its management. ${ }^{19}$

Recent evidence from Bangladesh and India highlighted that access to routine health services and medication was seriously disrupted during the pandemic. ${ }^{20}{ }^{21}$ A few studies conducted in the Rohingya camps amid this pandemic found that alongside the limited available healthcare facilities, healthcare service delivery can be seriously disrupted due to lockdown measures and social isolation. ${ }^{22} 23$ The restriction measures, including the government's stay-at-home orders, maintaining quarantine and isolation measures, affected both the general population $^{24}$ and Rohingya refugees ${ }^{14}$ in Bangladesh. As a part of nationwide lockdown, public transportation, the most popular means of transportation, was ceased to restrict mass movement. Such halt of transportation service meant no vehicular means to go to health facilities. Research has also documented that lockdown measures adopted to contain the spread of coronavirus has caused disruptions in the delivery of essential health services in the Rohingya camps. ${ }^{14}$ This could result in limited access to routine health services and medications and increased their difficulties and vulnerability to the burden of diseases. ${ }^{14} 25$

However, no previous studies have explored the difficulties faced by Rohingya older adults in receiving medicine and routine medical care during this pandemic. This study, therefore, aimed to address this gap, by examining the difficulties faced by the Rohingya older adults in accessing routine medical care and medications during the pandemic. We anticipate and thus hypothesise that Rohingya older adults faced greater difficulties in accessing routine medical care and medications during the pandemic.

\section{METHODS \\ Study design and participants}

This study followed a cross-sectional design and was carried out among 416 Rohingya older adults aged 60 years and above residing in camps situated in the Cox's Bazar district in the South-Eastern part of Bangladesh in October 2020. The detailed method of the study is presented elsewhere. ${ }^{19}$ The inclusion criteria included age $\geq 60$ years and Rohingya Forcibly Displaced Myanmar Nationals (FDMN) status. Participants were excluded if they self-reported having any of the following criteria: adverse mental conditions (clinically diagnosed schizophrenia, bipolar mood disorder, dementia/cognitive impairment), a hearing disability or were unable to communicate with researchers.

\section{Measures}

\section{Outcome measure}

This study's primary outcome variable was difficulties faced by the participants in getting medicine, and the secondary outcome was difficulties faced by the participants in receiving routine medical care during the COVID-19 pandemic. The participants were asked the following questions: 'How much difficulty do you have accessing the medicine that you need because of the COVID-19 pandemic or social distancing rules?' and 'How much difficulty do you have receiving routine medical care that you need because of the COVID-19 pandemic restrictions imposed by Government of Bangladesh?'. The responses were dichotomised ( $0=$ no difficulties and $1=$ difficulties faced).

\section{Explanatory variables}

An extensive review of available studies guided the selection of explanatory variables. ${ }^{522627}$ Explanatory variables 
included age (categorised as 60-69, 70-79, and $\geq 80$ years), sex (male/female), marital status (married/widowed), family size ( $\leq 4$ and more than 4 ), literacy (unable to read and write/able to read and write), living arrangements (living with family /living alone), memory or concentration problem (no problem/low memory or concentration), walking distance from to the nearest health centre ( $<30 \mathrm{~min} / \geq 30 \mathrm{~min}$ ), frequency of communication during COVID-19 (less than previous/same as previous), feeling of loneliness (hardly/sometimes to often), perceived that older adults required additional care during COVID-19 (yes/no), pre-existing non-communicable chronic conditions (yes/no) and perceived that older adults at highest risk of COVID-19 (yes/no).

\section{Data collection tools and techniques}

A pretested semistructured questionnaire in Bengali language was used to collect the information through faceto-face interviews. Data were electronically recorded in Survey CTO mobile app (https://www.surveycto.com/) by two data collectors, who were local residents of Cox's Bazar, fluent in Rohingya dialects and had previous experience of administering health surveys in electronic platform. The surveyors were trained extensively before the data collection through a half-day Zoom meeting on the data collection tools and techniques as well as procedures for maintaining COVID-19 safe behaviours during the data collection. During data collection, surveyors practised COVID-19 safety measures such as using facemasks, maintaining social distancing and practising cough etiquettes by covering coughs and sneezes with disposable tissues or clean clothes. Additionally, interviews were conducted in an open space outside participants' households while maintaining the confidentiality of their responses.

The English version of the questionnaire was first translated to Bengali language and then back-translated to English by two researchers to ensure the contents' consistency. The Bengali version of the tool was piloted among a small sample $(n=10)$ of Rohingya older adults from the selected camp to refine the language in the final version. No changes were made following the pretest in the final tool. Data collection was accomplished using this final tool through face-to-face interviews of the participants and each of the interviews took around half an hour.

\section{Statistical analysis}

The distribution of the variables was assessed through descriptive analysis. $\chi^{2}$ tests compared the prevalence of the outcome variables within different categories of explanatory variables with a $5 \%$ level of significance. We used a binary logistic regression model to determine the association of outcome variables with explanatory variables. The final model includes only the variables with $\mathrm{p}<0.25$ in the unadjusted analysis. ${ }^{28}$ Both unadjusted and adjusted ORs (AOR) are reported with a 95\% CI. We also performed the model diagnostics, such as multicollinearity and area under the curve in the model. All analyses were performed using the statistical software package Stata (V.14.0).

\begin{tabular}{|c|c|c|}
\hline Characteristics & $\mathbf{n}$ & $\%$ \\
\hline \multicolumn{3}{|l|}{ Age (year) } \\
\hline $60-69$ & 308 & 74.0 \\
\hline $70-79$ & 83 & 20.0 \\
\hline$\geq 80$ & 25 & 6.0 \\
\hline \multicolumn{3}{|l|}{ Sex } \\
\hline Male & 251 & 60.3 \\
\hline Female & 165 & 39.7 \\
\hline \multicolumn{3}{|l|}{ Marital status } \\
\hline Married & 389 & 93.5 \\
\hline Widowed & 27 & 6.5 \\
\hline \multicolumn{3}{|l|}{ Family size } \\
\hline$\leq 4$ & 167 & 40.1 \\
\hline$>4$ & 249 & 59.9 \\
\hline \multicolumn{3}{|l|}{ Literacy } \\
\hline Unable to read and write & 406 & 97.6 \\
\hline Able to read and write & 10 & 2.4 \\
\hline \multicolumn{3}{|l|}{ Living arrangement } \\
\hline Living with family & 362 & 87.0 \\
\hline Living alone & 54 & 13.0 \\
\hline
\end{tabular}

\section{Ethical approval}

Both verbal and written informed consents were sought from the participants before administering the survey. Participation was voluntary, and participants did not receive any compensation. Written approval was also sought from the Office of the Refugee Relief and Repatriation Commissioner prior to accessing the camps.

Patient and public involvement

Patients and/or the public were not involved in developing research questions, designing, and conducting the study, and disseminating the results.

\section{RESULTS}

\section{Participants' characteristics}

The majority of the participants were aged 60-69 years $(74.0 \%)$, male $(60.3 \%)$, married $(93.5 \%)$ and illiterate $(97.6 \%)$. Around $60 \%$ of respondents belonged to a family of greater than four and more than 1 in 10 participants $(13 \%)$ reported living alone (table 1). Overall, $30 \%$ of the participants reported difficulties accessing both medicine (primary outcome) and routine medical care (secondary outcome) (table 2).

\section{Bivariate analyses of difficulties receiving medical care services}

Table 2 shows the bivariate analyses between participants' characteristics and the primary and secondary outcomes. Difficulties in accessing medicine were significantly more likely among participants living 
Table 2 Bivariate analysis of difficulties faced in accessing medical services amid COVID-19 pandemic by older Rohingya (forcibly displaced Myanmar nationals) adults and selected background characteristics ( $\mathrm{N}=416)$

\begin{tabular}{|c|c|c|c|c|}
\hline \multirow[b]{2}{*}{ Characteristics } & \multicolumn{2}{|c|}{$\begin{array}{l}\text { Experienced difficulties } \\
\text { accessing medicine }\end{array}$} & \multicolumn{2}{|c|}{$\begin{array}{l}\text { Experienced difficulties } \\
\text { receiving routine medical care }\end{array}$} \\
\hline & n (\%) & P-value & n (\%) & P-value \\
\hline Overall & $120(30.2)$ & & $118(30.0)$ & \\
\hline \multicolumn{5}{|l|}{ Age (year) } \\
\hline $60-69$ & $93(31.5)$ & 0.615 & $89(30.5)$ & 0.887 \\
\hline $70-79$ & $21(25.9)$ & & $22(27.9)$ & \\
\hline$\geq 80$ & $6(28.6)$ & & $7(31.8)$ & \\
\hline \multicolumn{5}{|l|}{ Sex } \\
\hline Male & $64(26.5)$ & 0.040 & $60(25.1)$ & 0.008 \\
\hline Female & $56(36.1)$ & & $58(37.7)$ & \\
\hline \multicolumn{5}{|l|}{ Family size } \\
\hline $0-4$ & $44(27.9)$ & 0.401 & $46(28.9)$ & 0.696 \\
\hline$>4$ & 76 (31.8) & & $72(30.8)$ & \\
\hline \multicolumn{5}{|l|}{ Living arrangement } \\
\hline Living with family & 98 (28.3) & 0.032 & $99(29.2)$ & 0.373 \\
\hline Living alone & $22(43.1)$ & & $19(35.2)$ & \\
\hline \multicolumn{5}{|l|}{ Problem in memory or concentration } \\
\hline No problem & $93(27.4)$ & 0.002 & $99(29.5)$ & 0.556 \\
\hline Low memory or concentration & $27(47.4)$ & & 19 (33.3) & \\
\hline \multicolumn{5}{|c|}{ Walking distance to the nearest health centre } \\
\hline$<30 \min$ & $86(27.6)$ & 0.027 & $71(23.1)$ & $<0.001$ \\
\hline$\geq 30 \min$ & $34(40.0)$ & & $47(55.3)$ & \\
\hline \multicolumn{5}{|c|}{ Frequency of communication during COVID-19 } \\
\hline Same as previous & $19(11.5)$ & $<0.001$ & $23(13.8)$ & $<0.001$ \\
\hline Less than previous & $101(43.7)$ & & $95(42.0)$ & \\
\hline \multicolumn{5}{|l|}{ Feeling of loneliness } \\
\hline Hardly & $65(24.2)$ & $<0.001$ & $66(24.6)$ & $<0.001$ \\
\hline Sometimes to often & $55(43.0)$ & & $52(41.6)$ & \\
\hline \multicolumn{5}{|c|}{ Perceived that older adults at highest risk of COVID-19 } \\
\hline No & $17(11.5)$ & $<0.001$ & $20(13.7)$ & $<0.001$ \\
\hline Yes & $103(41.4)$ & & $98(39.7)$ & \\
\hline \multicolumn{5}{|c|}{ Perceived that older adults required additional care during COVID-19 } \\
\hline No & $49(16.6)$ & $<0.001$ & $54(18.4)$ & $<0.001$ \\
\hline Yes & $71(70.3)$ & & $64(64.7)$ & \\
\hline \multicolumn{5}{|c|}{ Having existing non-communicable chronic conditions } \\
\hline No & $71(25.6)$ & 0.002 & $85(30.7)$ & 0.659 \\
\hline Yes & $49(40.8)$ & & $33(28.5)$ & \\
\hline
\end{tabular}

alone $(43 \%)$, with memory or concentration problems $(47 \%)$, communicating less frequently during the pandemic than before $(43 \%)$, residing more than 30 min (walking distance) away from nearest health centre $(40 \%)$, feeling lonely (43\%), perceiving that older adults are at highest risk of COVID-19 (41\%), required additional care $(70 \%)$ and had one or more noncommunicable chronic conditions (41\%). Likewise, participants' characteristics associated with significant difficulties receiving routine medical care included female sex, residing more than 30 min walking distance from nearest health centre $(55 \%)$, communicating less frequently during the pandemic than before $(42 \%)$, feeling lonely $(41.6 \%)$ and perceiving that older adults are at highest risk of COVID-19 (40\%), and required additional care $(65 \%)$ (table 2 ). 
Factors associated with difficulties in receiving medical care services

Table 3 shows the unadjusted and adjusted factors associated with difficulties in receiving medical care services. The multicollinearity among the covariates was checked and a variance inflation factor of less than five was observed for each covariate in both models, meaning that no multicollinearity was present (online supplemental annex 1). The area under the Receiver Operating Characteristic (ROC) curve of 0.85 and 0.81 , respectively, in two models (online supplemental annex 2) represents good discrimination. In the adjusted model, loneliness and perceptions that older adults are at the highest risk of COVID-19 and require additional care during COVID-19 were significantly associated with perceived difficulties accessing medicines. Participants who reported loneliness (AOR 3.54, 95\% CI 1.93 to 6.48) and perceived that older adults are at the highest risk of COVID-19 (AOR $3.35,95 \%$ CI 1.61 to 6.97 ) had more than three times higher odds of experiencing difficulties accessing medicine than their respective counterparts. Similarly, participants perceiving that older adults required additional care during the pandemic were around seven times more likely to face difficulties accessing medicine than those who did not feel so (AOR 6.89, 95\% CI 3.62 to 13.13).

Meanwhile, a separate adjusted analysis revealed that participants residing more than 30 min of walking distance from the nearest health centre had nearly four times increased odds of experiencing difficulties receiving routine medical care than those residing near (AOR $3.57,95 \%$ CI 1.95 to 6.56 ). Similarly, participants who felt loneliness were more than twice more likely to have difficulties receiving routine medical care than those who did not feel so (AOR 2.20, 95\% CI 1.25 to 3.87). Participants who perceived that older adults are at the highest risk of COVID-19 had nearly three times higher odds of facing difficulties in receiving routine medical care than those who did not have that concern (AOR 2.85, 95\% CI 1.36 to 5.99). Also, older adults who perceived that they required additional care during the pandemic were around five times more likely to face difficulties receiving routine medical care (AOR 4.55, 95\% CI 2.48 to 8.35 ).

\section{DISCUSSION}

This study examined the difficulties experienced by older Rohingya adults in accessing medicines and routine medical care services during the COVID-19 pandemic in Bangladesh. Overall, 30\% of the participants reported difficulties accessing medicine and routine medical care during the COVID-19 pandemic. We did not find any single study on older refugees in Bangladesh and other countries to compare this finding with. However, existing studies conducted among younger Rohingya refugees in Bangladesh, ${ }^{19}$ child refugees in England, ${ }^{29}$ refugees and asylum seekers in Switzerland ${ }^{30}$ and Syrian refugees in Germany ${ }^{31}$ reported several barriers associated with refugees' access to medicine and routine healthcare, including poor literacy of older refugees, ${ }^{19}$ language and legal barriers and travel costs. ${ }^{32}$ Furthermore, several studies indicated that limited long-term clinical care facilities for older individuals, limited/unavailability of medicines, inadequate knowledge about available services and healthcare system, inadequate 'cultural competence of the healthcare providers, age-related self-stigma and financial constraints were the primary reasons that refugees experienced difficulties in accessing medical services. ${ }^{32-36}$ Notably, inadequate preparedness for enhancing healthcare services, the efforts to contain the pandemic, and coronavirus-related travel restrictions impede older Rohingyas' access to healthcare during the pandemic. ${ }^{33} 34$ In Bangladesh, the general barriers that make healthcare facilities inaccessible during the pre-COVID and post-COVID period include a lack of healthcare system capacity, weak management and unrestrained corruption. ${ }^{37}$ Thus, we believe that the combination of multiple factors hindered the participants' access to medicine and routine medical care during the COVID-19 pandemic. Therefore, the current study highlights the need to make healthcare accessible during the COVID-19 pandemic.

In our study, older Rohingya adults who felt loneliness experienced greater difficulties accessing medicine and routine medical care than those who did not feel loneliness. Refugee and displaced people often find it difficult to mix with family, friends, and community members, and feel lonely. ${ }^{38}$ If such loneliness remains unresolved, it can lead to depression and anxiety. ${ }^{39}$ Our study's finding broadly corroborates a study carried out among Syrian refugees in Turkey, which indicates that refugees with depression and anxiety were likely to experience difficulties accessing sufficient healthcare services. ${ }^{40}$ Older Rohingya adults' feeling of loneliness may be due to the challenges the COVID-19 pandemic brought to refugees, including lockdowns, self-isolation/quarantine, ${ }^{36}$ limited social networks, inadequate connection with family members and limited social and psychological support. ${ }^{41-43}$ Moreover, stigma, racism and discrimination are postulated to increase loneliness in refugees worldwide. ${ }^{36} 4244$ Therefore, it is vital to strengthen the measures to improve the communication between people within the camps as well as with people beyond the camps.

Perceptions that older individuals are at a higher risk of COVID-19 infection and require additional care during the pandemic were associated with perceived difficulties accessing medicines and receiving routine medical care. These findings, to our knowledge, are novel. The association of perceived higher risk of COVID-19 with limited access to medicine and receiving routine medical care may have reverse causation-that is, access to health care makes them feel less vulnerable and less lonely. Future research should apply a longitudinal design to provide insights into the causal mechanisms underlying the relationships between perceived higher risk of COVID-19 and access to 
Table 3 Factors associated with difficulties faced by older Rohingya (forcibly displaced Myanmar nationals) adults in accessing medical services amid COVID-19 pandemic in Bangladesh

Experienced difficulties receiving routine

Experienced difficulties accessing medicine medical care

$\begin{array}{llllllllllll}{ }^{*} \mathrm{COR} & 95 \% \mathrm{Cl} & \text { †AOR } & 95 \% \mathrm{Cl} & & { }^{*} \mathrm{COR} & 95 \% \mathrm{Cl} & \text { †AOR } & 95 \% \mathrm{Cl}\end{array}$

\begin{tabular}{|c|c|c|c|c|c|c|c|}
\hline \multicolumn{8}{|l|}{ Age (year) } \\
\hline $60-69$ & \multicolumn{2}{|l|}{1.00} & \multicolumn{2}{|c|}{$\begin{array}{l}\text { Not taken in the final } \\
\text { model }\end{array}$} & \multicolumn{2}{|l|}{1.00} & $\begin{array}{l}\text { Not taken in the fina } \\
\text { model }\end{array}$ \\
\hline $70-79$ & 0.76 & 0.44 to 1.32 & & & 0.88 & 0.51 to 1.53 & \\
\hline$\geq 80$ & 0.42 & 0.33 to 2.31 & & & 1.06 & 0.42 to 2.70 & \\
\hline \multicolumn{8}{|l|}{ Sex } \\
\hline Male & 1.00 & & 1.00 & & 1.00 & & 1.00 \\
\hline Female & 1.57 & 1.02 to 2.43 & 1.30 & 0.75 to 2.26 & 1.80 & 1.16 to 2.79 & 0.88 to 2.52 \\
\hline \multicolumn{8}{|l|}{ Family size } \\
\hline $0-4$ & 1.00 & & \multicolumn{2}{|c|}{$\begin{array}{l}\text { Not taken in the final } \\
\text { model }\end{array}$} & 1.00 & & $\begin{array}{l}\text { Not taken in the final } \\
\text { model }\end{array}$ \\
\hline$>4$ & 1.21 & 0.78 to 1.88 & & & 1.09 & 0.70 to 1.70 & \\
\hline \multicolumn{8}{|l|}{ Living arrangement } \\
\hline $\begin{array}{l}\text { Living with other family } \\
\text { members }\end{array}$ & 1.00 & & 1.00 & & 1.00 & & $\begin{array}{l}\text { Not taken in the final } \\
\text { model }\end{array}$ \\
\hline Living alone & 1.92 & 1.05 to 3.50 & 0.67 & 0.29 to 1.52 & 1.32 & 0.72 to 2.41 & \\
\hline \multicolumn{8}{|c|}{ Problem in memory or concentration } \\
\hline No problem & 1.00 & & 1.00 & & 1.00 & & $\begin{array}{l}\text { Not taken in the final } \\
\text { model }\end{array}$ \\
\hline $\begin{array}{l}\text { Low memory or } \\
\text { concentration }\end{array}$ & 2.39 & 1.35 to 4.24 & 1.42 & 0.65 to 3.08 & 1.20 & 0.66 to 2.18 & \\
\hline \multicolumn{8}{|c|}{$\begin{array}{l}\text { Walking distance from the nearest } \\
\text { health centre }\end{array}$} \\
\hline$<30 \mathrm{~min}$ & 1.00 & & 1.00 & & 1.00 & & 1.00 \\
\hline$\geq 30 \min$ & 1.75 & 1.06 to 2.89 & 1.00 & 0.51 to 1.96 & 4.13 & 2.50 to 6.83 & 1.95 to 6.56 \\
\hline
\end{tabular}

Frequency of communication during COVID-19

\begin{tabular}{|c|c|c|c|c|c|c|c|c|}
\hline Same as previous & 1.00 & & 1.00 & & 1.00 & & 1.00 & \\
\hline Less than previous & 6.01 & 3.49 to 10.36 & 1.90 & 0.92 to 3.93 & 4.54 & 2.72 to 7.59 & 1.54 & 0.73 to 3.24 \\
\hline \multicolumn{9}{|l|}{ Feeling of loneliness } \\
\hline Hardly & 1.09 & & 1.00 & & 1.09 & & 1.00 & \\
\hline Sometimes to often & 2.36 & 1.51 to 3.70 & 3.54 & 1.93 to 6.48 & 2.18 & 1.39 to 3.42 & 2.20 & 1.25 to 3.87 \\
\hline
\end{tabular}

Perceived that older adults at highest risk of COVID-19

\begin{tabular}{|c|c|c|c|c|c|c|c|c|}
\hline No & 1.00 & & 1.00 & & 1.00 & & 1.00 & \\
\hline Yes & 5.44 & 3.09 to 9.56 & 3.35 & 1.61 to 6.97 & 4.14 & 2.42 to 7.08 & 2.85 & 1.36 to 5.99 \\
\hline \multicolumn{9}{|c|}{$\begin{array}{l}\text { Perceived that older adults required additional care } \\
\text { during COVID-19 }\end{array}$} \\
\hline No & 1.00 & & 1.00 & & 1.00 & & 1.00 & \\
\hline Yes & 11.93 & 7.05 to 20.18 & 6.89 & 3.62 to 13.13 & 8.13 & 4.90 to 13.49 & 4.55 & 2.48 to 8.35 \\
\hline
\end{tabular}

Having existing non-communicable chronic conditions

\begin{tabular}{llllllll} 
No & 1.00 & & 1.00 & & 1.00 & & $\begin{array}{l}\text { Not taken in the final } \\
\text { model }\end{array}$ \\
Yes & 2.00 & 1.27 to 3.15 & 1.26 & 0.66 to 2.43 & 0.90 & 0.56 to 1.45 \\
\hline
\end{tabular}




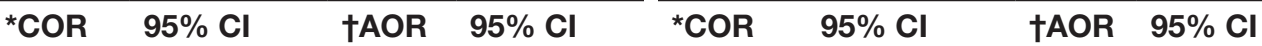

\author{
${ }^{*}$ Crude Odds Ratio \\ †Adjusted Odds Ratio
}

medicine and receiving routine medical care. Many factors may shape older Ronhigya adults' perceived higher risk of COVID-19 and access to medicine and receiving routine medical care. Older Rohingya adults tend to get infected with the coronavirus and die from the disease more than younger individuals. ${ }^{45} 46$ This may be because older individuals are more likely to have a greater risk of chronic diseases, thus requiring additional care. ${ }^{31}$ Evidence indicates that thousands of older Rohingya adults experienced communicable and non-communicable diseases, including diabetes, liver disease, hepatitis (B and $\mathrm{C}$ ), diarrhoea, measles, diphtheria, unexplained fever, HIV and tuberculosis. $^{3447}$ The experiences of these diseases, together with limited PPE and medical services (such as the absence of telehealth medical care and face-to-face consultations for medical services), may likely increase their COVID-19 risk and hinder their choices about accessing medicines and receiving routine medical care. Therefore, policy-makers need to pay more attention to targeted intervention programmes for older FDMNs, who require additional care and are at a higher risk during the COVID-19 pandemic.

Our study found that older Rohingya adults who were residing beyond $30 \mathrm{~min}$ walking distance of a healthcare centre had higher odds of difficulties receiving routine medical care. This finding is widely consistent with two studies conducted among ethnic minorities in Myanmar ${ }^{48}$ and the refugees in Uganda. ${ }^{49}$ The former study indicates that ethnic minorities residing within 5 $\mathrm{km}$ to the closest healthcare facilities were more likely to pay outpatient visits than those living beyond $5 \mathrm{~km}$. The Ugandan study suggests that the geographical accessibility of medical care facilities for both refugees and nationals varied significantly: more nationals resided within $5 \mathrm{~km}$ radius of public medical facilities than refugees, thus incurring transport costs for refugees. ${ }^{49}$ In the refugee camps in Bangladesh, there are limited routine medical care facilities located within walking distance for the Rohingya population. ${ }^{34}$ Limited transportation facilities further restricted such inadequate healthcare facilities during the pandemic. ${ }^{50}$ Moreover, the COVID-19 outbreak creates fear that going out for receiving distant medical services may risk their own and family members' health. ${ }^{46}$ Rohingya older adults are particularly vulnerable in this regard because of their physical disabilities (eg, vision impairment and diminishing hearing capacity) in accessing routine medical care. ${ }^{51}$ Moreover, many of their diseases go untreated due to long distance, acute financial constraints, low self-esteem, limited trust in medical care, unfriendly treatment, cultural incompetency and discrimination. ${ }^{34} 52$ These issues are substantiated by the findings from studies conducted among Rohingya, Chin and Kachin refugees living in Malaysia ${ }^{53}$ and refugees in Uganda. ${ }^{49}$ Thus, the current study suggests that various challenges shape older Rohingyas adults' access to medical services.

\section{Implications for policy and practice}

Our findings highlight the need of coordination between relevant stakeholders, policy-makers and development partners to undertake appropriate interventions to address the difficulties Rohingya older adults experienced in accessing medicine and routine medical services during the COVID-19 pandemic in Bangladesh. Specifically, relevant stakeholders, policy-makers and development partners need to provide distant and targeted strategies to improve the access of older refugees, who are lonely or have higher healthcare needs, to healthcare needs. Statelessness is a complex issue and requires multisectorial and collective international efforts. Given the critical role played by the Office of the Refugee Relief and Repatriation Commissioner under the Government of Bangladesh, as the key policy-maker for the Rohingya population, we believe that they will be an indispensable partner to address the barriers of the camp people in accessing medical care during this crisis. International organisations such as UNHCR, International Organisation for Migration, Concern Worldwide and Medecins Sans Frontieres are actively working at the forefront with this vulnerable population. These organisations along with local organisations such as BRAC, Society for Health Extension and Development and Social Assistance and Rehabilitation for the Physically Vulnerable could play an important role in supporting the Office of the Refugee Relief and Repatriation Commissioner in designing and implementing people centred interventions to provide continuing care.

It is also equally important that the refugee community are engaged in the camp environment in development of preparedness and responses plan to overcome the barriers that they are experiencing. This may allow the health sector and relevant stakeholders to promptly plan people centred strategies required to address the barriers that they are facing in accessing health services. ${ }^{54}$ Engaging local community leaders can be of great value achieving meaningful community engagement, effective 
communication, and prompt responses during this public health emergency and beyond..$^{55}$ Local community organisations which are aimed to improve the health of vulnerable refugee communities should facilitate community engagement through the dissemination of information and improving health literacy among the people, thereby improving their decision making capacity. ${ }^{56}$ Community health workers (CHWs) have been strong pillars of health services in low-income and middle-income countries, including Bangladesh. ${ }^{57}$ CHWs have been successfully mobilised to undertake different roles such as health assessment, resource linking, facilitating treatment, healthcare navigation, health education and psychosocial support. ${ }^{589}$ Hence, we believe that training females and youths from the local camps as community health workers could be an innovative approach to involve and empower the local community as well as devise socioculturally tailored interventions.

\section{Strength and limitations}

The current study has several strengths. First, this study is unique because, to our knowledge, it is the first study that explicitly examined older Rohingya adults' difficulties accessing medical services during the COVID-19 pandemic in Bangladesh. This study adds to the small number of international literature exploring the refugees' difficulties accessing medical services during the COVID-19 pandemic. Second, the study area and population were distinctive because the Rohingya refugee camps were the biggest in the world, and Rohingya people were one of the most persecuted minorities globally. ${ }^{43}$

Despite these strengths, our study's findings should be considered in the context of several limitations. First, given the restrictions around our ability to collect data, this study used purposive sampling for both the study site and participants, therefore, there is a possibility for selection bias limiting the generalisability of the findings to the entire population of Rohingya older adults in the camps. Second, our research was cross-sectional in nature. Therefore, causality cannot be established. Third, our study is limited to quantitative analysis, as we did not explore the qualitative aspects of older Rohingya adults' experience of difficulties in accessing medicines and receiving medical care during the pandemic. Additionally, data were collected using self-report and thus could be subjected to recall and social desirability bias. However, we believe the recall bias to be minimal as our questions included recall of recent events related to the enduring COVID-19 pandemic. To decrease the risk of social desirability bias, questions were structured in simple language, focused neutral in content and tone, so that the participants would feel comfortable responding truthfully.

\section{Directions for future research}

Considering the importance of the issue in the current scenario and limitations of our research, we hereby make a strong call for future research. Future research should be focused on providing insights into the causal mechanisms underlying the relationships between perceived higher risk of COVID-19 and access to medicine and receiving routine medical care applying a longitudinal design. Another arena for further research would be exploring the experience of difficulties and the barriers/ enablers related to accessing medicines and receiving medical care during the COVID-19 pandemic utilising a mixed-method approach. This will provide a better understanding of unique needs among the Rohingya older adults from their own perspectives and give voice to the most vulnerable refugee communities in the world.

\section{CONCLUSION}

Overall, we found that many Rohingya older adults reported facing difficulties accessing routine medical care and medications. It is critical to address these barriers to care as this population is at increased risk of health and economic implications from COVID-19, and often requires routine medical support. Key factors influencing access were distance to healthcare facilities, loneliness and perceived vulnerability of older people (risk of COVID-19 and need for care). Strategies need to not only improve the availability of healthcare but also address the vulnerable psychological state of older people. Policymakers, healthcare practitioners and local stakeholders should immediately revise the emergency preparedness plan to incorporate strategies to address the gaps in access to routine medical services for older people in the camps. The current study also advocates a strong call for future research aimed to examine the experience of difficulties and the barriers/enablers related to accessing medicines and receiving medical care during the COVID-19 pandemic among the older Rohingya adults using a mixed-method approach.

\section{Author affiliations}

${ }^{1}$ ARCED Foundation, Dhaka, Bangladesh

${ }^{2}$ Centre for Primary Health Care and Equity, University of New South Wales, Sydney, New South Wales, Australia

${ }^{3}$ BRAC James P Grant School of Public Health, BRAC University, Dhaka, Bangladesh ${ }^{4}$ Department of Public Health, Daffodil International University, Dhaka, Bangladesh

${ }^{5}$ Global Research and Data Support, Innovations for Poverty Action, New Haven, Connecticut, USA

${ }^{6}$ National Centre for Epidemiology and Population Health, Research School of Population Health, Australian National University, Canberra, Australian Capital Territory, Australia

${ }^{7}$ School of Health Sciences, Western Sydney University, Campbeltown, New South Wales, Australia

${ }^{8}$ The School of Liberal Arts and Social Sciences, Independent University, Dhaka, Bangladesh

${ }^{9}$ Department of Sociology and Gerontology and Scripps Gerontology Center, Miami University, Oxford, Ohio, USA

${ }^{10}$ The George Institute for Global Health, Sydney, New South Wales, Australia

${ }^{11}$ School of Population and Public Health, The University of British Columbia, Vancouver, British Columbia, Canada

${ }^{12}$ Institute of Nutrition and Food Science, University of Dhaka, Dhaka, Bangladesh

${ }^{13}$ Dow Institute of Nursing and Midwifery, Dow University of Health Sciences, Karachi, Pakistan

Twitter ARM Mehrab Ali @mehrabbabu and Uday Narayan Yadav @UNYadav_ 
Acknowledgements We acknowledge the role of Sadia Sumaia Chowdhury, Programme Manager, ARCED Foundation and Md. Zahirul Islam, Project Associate, ARCED Foundation, for their support in data collection for the study.

Contributors This study was conceived and designed by SKM, AMA and UNY. SKM and AMA contributed to the data collection and analysis. SKM, AMA, UNY, MNH, SG, $\mathrm{MBH}, \mathrm{SR}$ and $\mathrm{RQ}$ contributed to writing the first draft of the manuscript. $\mathrm{AB}$ and $\mathrm{MH}$ commented extensively and edited the draft of the manuscript to finalise it. All authors read and approved the final version of the manuscript. SKM acting as the guarantor for the manuscript.

Funding The authors have not declared a specific grant for this research from any funding agency in the public, commercial or not-for-profit sectors.

Competing interests None declared.

Patient consent for publication Consent obtained directly from patient(s).

Ethics approval This study involves human participants and was approved by The study protocol was approved by the Institutional Review Board of the Institute of Health Economics, University of Dhaka, Bangladesh (Ref: IHE/2020/1037).

Provenance and peer review Not commissioned; externally peer reviewed.

Data availability statement Data are available on reasonable request. Not applicable.

Supplemental material This content has been supplied by the author(s). It has not been vetted by BMJ Publishing Group Limited (BMJ) and may not have been peer-reviewed. Any opinions or recommendations discussed are solely those of the author(s) and are not endorsed by BMJ. BMJ disclaims all liability and responsibility arising from any reliance placed on the content. Where the content includes any translated material, BMJ does not warrant the accuracy and reliability of the translations (including but not limited to local regulations, clinical guidelines, terminology, drug names and drug dosages), and is not responsible for any error and/or omissions arising from translation and adaptation or otherwise.

Open access This is an open access article distributed in accordance with the Creative Commons Attribution Non Commercial (CC BY-NC 4.0) license, which permits others to distribute, remix, adapt, build upon this work non-commercially, and license their derivative works on different terms, provided the original work is properly cited, appropriate credit is given, any changes made indicated, and the use is non-commercial. See: http://creativecommons.org/licenses/by-nc/4.0/.

\section{ORCID iDs}

Sabuj Kanti Mistry http://orcid.org/0000-0001-6100-6076

ARM Mehrab Ali http://orcid.org/0000-0001-5442-7147

Md. Belal Hossain http://orcid.org/0000-0003-4603-863X

\section{REFERENCES}

1 WHO. WHO coronavirus disease (COVID-19) Dashboard, 2020. Available: https://covid19.who.int/ [Accessed 07 Dec 2020].

2 Miller EA. Protecting and improving the lives of older adults in the COVID-19 era. J Aging Soc Policy 2020;32:297-309.

3 . Severe outcomes among patients with coronavirus disease 2019 (COVID-19) - United States, February 12-March 16, 2020. MMWR Morb Mortal Wkly Rep 2020;69:343-6.

4 Applegate WB, Ouslander JG. COVID-19 presents high risk to older persons. J Am Geriatr Soc 2020;68:681.

5 Laires PA, Dias S, Gama A, et al. The association between chronic disease and serious COVID-19 outcomes and its influence on risk perception: survey study and database analysis. JMIR Public Health Surveill 2021;7:e22794.

6 Morley JE, Vellas B. COVID-19 and older adult. . Springer, 2020: 24. 364-5.

7 Raju E, Ayeb-Karlsson S. COVID-19: how do you self-isolate in a refugee camp? Int J Public Health 2020;65:515-7.

8 Refugees International. COVID-19 and the displaced: addressing the threat of the novel coronavirus in humanitarian emergencies, 2020. Available: https://www.refugeesinternational.org/reports/2020/3/29/ covid-19-and-the-displaced-addressing-the-threat-of-the-novelcoronavirus-in-humanitarian-emergencies [Accessed 06 Nov 2020].

9 UNHCR. Coronavirus outbreak, 2020. Available: https://www.unhcr. org/en-us/coronavirus-covid-19.html [Accessed 22 Oct 2020].

10 Transcript of Secretary-General's remarks at press encounter with President of the World Bank, Jim Yong Kim 2018.

11 BBC. Myanmar Rohingya: what you need to know about the crisis, 2020. Available: https://www.bbc.com/news/world-asia-41566561
12 reliefweb. The Rohingya Amongst Us": Bangladeshi Perspectives on the Rohingya Crisis Survey, 2018. Available: https://reliefweb.int/ report/bangladesh/rohingya-amongst-us-bangladeshi-perspectivesrohingya-crisis-survey

13 UNHCR. Rohingya Refugee Response - Bangladesh Factsheet Protection (June 2020), 2020. Available: https://reliefweb.int/report/ bangladesh/rohingya-refugee-response-bangladesh-factsheetprotection-june-2020

14 Kamal A-H, Huda M, Dell C. Translational strategies to control and prevent spread of COVID-19 in the Rohiynga refugee camps in Bangladesh. Global Biosecurity 2020;1

15 World Vision Bangladesh. Rohingya refugee response COVID-19 report, 2020

16 Organization WH. Rohingya Crisis Situation Report \#19, 2021 Available: https://cdn.who.int/media/docs/default-source/searo/ bangladesh/bangladesh-rohingya-crisis-pdf-reports/sitreps/2021/ who-cox-s-bazar-situation-report-19.pdf?sfvrsn=8ee2bd5f 7 [Accessed 27 Oct 2021].

17 Group ISC. Situation Report: Rohingya Refugee Crisis, Cox's Bazar, 2018. Available: https://www.humanitarianresponse.info/sites/www. humanitarianresponse.info/files/documents/files/180325_iscg_sitrep. final .pdf

18 Yadav UN, Rayamajhee B, Mistry SK, et al. A syndemic perspective on the management of non-communicable diseases amid the COVID-19 pandemic in low- and middle-income countries. Front Public Health 2020;8:508.

19 Mistry SK, Ali ARMM, Yadav UN, et al. Misconceptions about COVID-19 among older Rohingya (forcefully displaced Myanmar nationals) adults in Bangladesh: findings from a cross-sectional study. BMJ Open 2021;11:e050427.

20 Pati S, Mahapatra P, Kanungo S, et al. Managing multimorbidity (multiple chronic diseases) amid COVID-19 pandemic: a community based study from Odisha, India. Front Public Health 2020;8:1026

21 Reza HM, Sultana F, Khan IO. Disruption of healthcare amid COVID-19 pandemic in Bangladesh. Open Public Health $J$ 2020;13:438-40.

22 Barua A, Karia RH. Challenges faced by Rohingya refugees in the COVID-19 pandemic. Ann Glob Health 2020;86:129.

23 Guglielmi S, Seager J, Mitu K, et al. Exploring the impacts of COVID-19 on Rohingya adolescents in Cox's Bazar: a mixedmethods study. J Migr Health 2020;1-2:100031.

24 Anwar S, Nasrullah M, Hosen MJ. COVID-19 and Bangladesh: challenges and how to address them. Front Public Health 2020;8:154

25 Hossain MA, Huda MN, AKMA U. Risk factors, contemporary challenges and psychological well-being of the Rohingya refugees in Bangladesh: policy implications. Authorea 2021.

26 Mistry SK, ARMM A, Irfan NM. Prevalence and correlates of depressive symptoms among Rohingya (forcibly displaced Myanmar nationals or FDMNs) older adults in Bangladesh amid the COVID-19 pandemic. Global Mental Health 2021;8.

27 Yadav UN, Yadav OP, Singh DR, et al. Perceived fear of COVID-19 and its associated factors among Nepalese older adults in eastern Nepal: a cross-sectional study. PLoS One 2021;16:e0254825.

28 Agresti A. Building and applying logistic regression models. Categorical Data Analysis 2002:211-66.

29 Alkahtani S, Cherrill J, Millward C, et al. Access to medicines by child refugees in the East Midlands region of England: a crosssectional study. BMJ Open 2014;4:e006421.

30 Kiselev N, Morina N, Schick M. Barriers to access to outpatient mental health care for refugees and asylum seekers in Switzerland: the therapist's view. BMC Psychiatry 2020;20:1-14.

31 Aljadeeah S, Wirtz VJ, Nagel E. Barriers to accessing medicines among Syrian asylum seekers and refugees in a German federal state. Int J Environ Res Public Health 2021;18:519.

32 Merritt K, Pottie K. Caring for refugees and asylum seekers in Canada: early experiences and comprehensive global health training for medical students. Can Med Educ J 2020;11:e138.

33 Islam MM, Yunus MY. Rohingya refugees at high risk of COVID-19 in Bangladesh. Lancet Glob Health 2020;8:e993-4.

34 Kamal A-HM, Huda DMN, Dell DCA, et al. Translational strategies to control and prevent spread of COVID-19 in the Rohiynga refugee camps in Bangladesh. Global Biosecurity 2020;1.

35 Lebano A, Hamed S, Bradby H, et al. Migrants' and refugees' health status and healthcare in Europe: a scoping literature review. BMC Public Health 2020;20:1-22.

36 Benjamen J, Girard V, Jamani S, et al. Access to refugee and migrant mental health care services during the first six months of the COVID-19 pandemic: a Canadian refugee clinician survey. Int $J$ Environ Res Public Health 2021:18:5266. 
37 Al-Zaman MS. Healthcare crisis in Bangladesh during the COVID-19 pandemic. Am J Trop Med Hyg 2020;103:1357.

38 Doğan N, Dikeç G, Uygun E. Syrian refugees' experiences with mental health services in Turkey: "I felt lonely because I wasn't able to speak to anyone". Perspect Psychiatr Care 2019;55:673-80.

39 Mushtaq R, Shoib S, Shah T, et al. Relationship between loneliness, psychiatric disorders and physical health ? A review on the psychological aspects of loneliness. J Clin Diagn Res 2014;8:WE01.

40 Acarturk C, McGrath M, Roberts B, et al. Prevalence and predictors of common mental disorders among Syrian refugees in Istanbul, Turkey: a cross-sectional study. Soc Psychiatry Psychiatr Epidemiol 2021;56:475-84.

41 Mistry SK, Ali ARMM, Irfan NM, et al. Prevalence and correlates of depressive symptoms among Rohingya (forcibly displaced Myanmar nationals or FDMNs) older adults in Bangladesh amid the COVID-19 pandemic. Glob Ment Health 2021;8:1-24.

42 Johnson S, Bacsu J, Mclntosh T, et al. Social isolation and loneliness among immigrant and refugee seniors in Canada: a scoping review. Int J Migr Health Soc Care 2019;15:177-90.

43 Khan HTA, Rahman MA, Molla MH, et al. Humanitarian emergencies of Rohingya older people in Bangladesh: a qualitative study on hopes and reality. Ageing Int 2020;8:1-18.

44 Koehn S, Ferrer I, Brotman S. Between loneliness and belonging: narratives of social isolation among immigrant older adults in Canada. Ageing Soc 2020;60:1-21.

45 Niu S, Tian S, Lou J, et al. Clinical characteristics of older patients infected with COVID-19: a descriptive study. Arch Gerontol Geriatr 2020;89:104058.

46 Mistry SK, Ali ARMM, Akther F, et al. Are older adults of Rohingya community (Forcibly displaced Myanmar Nationals or FDMNs) in Bangladesh fearful of COVID-19? findings from a cross-sectional study. PLoS One 2021;16:e0253648.

47 Jubayer F, Kayshar S, Limon TI. First COVID-19 case in the Rohingya cAMP in Bangladesh: needs proper attention. Public Health 2021:191:20.

48 Tang K, Zhao Y, Li B, et al. Health inequity on access to services in the ethnic minority regions of northeastern Myanmar: a crosssectional study. BMJ Open 2017;7:e017770.
49 Kasozi J, Kasozi GK, Mayega RW. Access to health care by urban refugees and surrounding host population in Uganda. World J Public Health 2018;3:32.

50 Inter-Sector Coordination Group. In the shadow of the pandemic: the gendered impact of Covid-19 on Rohingya and host communities 2020.

51 Ahmed M, Whitestone N, Patnaik JL, et al. Burden of eye disease and demand for care in the Bangladesh Rohingya displaced population and host community: a cohort study. PLoS Med 2020;17:e1003096.

52 Alama MF, Al Amin Rabbyb VRP. The outbreak of COVID-19, response, and the vulnerabilities of Rohingya refugees in Bangladesh. International Journal of Innovation, Creativity and Change 2020;14:259-84.

53 Tay AK, Mung HK, Miah MAA, et al. An integrative adapt therapy for common mental health symptoms and adaptive stress amongst Rohingya, chin, and Kachin refugees living in Malaysia: a randomized controlled trial. PLoS Med 2020;17:e1003073.

54 World Health Organization. Role of community engagement in situations of extensive community transmission of COVID-19. Manila: WHO Regional Office for the Western Pacific, 2020.

55 Nutbeam $D$. The vital role of meaningful community engagement in responding to the COVID-19 pandemic. Public Health Res Pract 2021;31. doi:10.17061/phrp3112101. [Epub ahead of print: 1003 2021].

56 Abbas MZ. Public understanding and voluntary responsibility to mitigate COVID-19 pandemic: role of local community organizations in information sharing and health literacy. Asia Pac J Public Health 2021;33:451-2.

57 Pallas SW, Minhas D, Pérez-Escamilla R, et al. Community health workers in low- and middle-income countries: what do we know about scaling up and sustainability? Am J Public Health 2013;103:e74-82.

58 Hartzler AL, Tuzzio L, Hsu C, et al. Roles and functions of community health workers in primary care. Ann Fam Med 2018;16:240-5.

59 Mistry SK, Harris-Roxas B, Yadav UN, et al. Community health workers can provide psychosocial support to the people during COVID-19 and beyond in low- and middle- income countries. Front Public Health 2021;9:666753. 